\title{
The Secret to Being a Successful Online Instructor
}

Tammy Marino

\section{Southwestern Oregon Community College}

Over the past year, I have worked with many cohorts of teachers as they transition from teaching face-to-face to teaching online. As we explore best practices for creating and delivering quality online learning, the inevitable question comes up: How can I engage students and be a successful online instructor? To answer that question, let us first examine why teaching online feels different.

Teaching online can feel like a watered-down version of your personal teaching style. You set up the online environment to mirror what you would do in the classroom. You create discussion forums, assignments, assessments, and cross your fingers hoping it will all make sense for your students. You spend time on creating the instructional environment, hoping it is enough to support student learning. Yet you know a large chunk of the learning will take place without you. This can be an uninspiring thought.

What is missing? You! Your personality, style, enthusiasm, and teaching style. Those magical moments and interactions that help students get to know you as a person and a teacher. By infusing your online courses with YOU, the energy and excitement from teaching and learning will follow. Here are some questions and strategies to consider:

- Share about yourself. What do you want students to know about you? Do you love Star Wars? Are you a big fan of gardening? Think about the things that students would naturally find out about you if you were in a face-to-face class. Picture your classroom environment - do you enjoy a lot of color or natural light? Make a list of things you would share with students and look at ways to embed them in your online 
course. Pictures of your work environment, dog, or favorite movie are a great start. Then create a space and invite students to share as well. A discussion forum that is reserved for introductions can be an effective tool for students and you to share about yourself. You can also reserve time before live webinar sessions for "small talk" with students as they arrive.

- Choose engaging strategies that highlight your enthusiasm for the course content and teaching. If you love to perform and are not afraid of video, start recording yourself talking about a subject. Video not for you? Try recording your voice over a presentation. Or if live Zoom sessions sound better, schedule times for students to interact with you and their peers. The important thing is to use strategies that humanize you and allow you to share your excitement for the course topic.

- Create images, word clouds, or other visual representations of your expectations for students and your teaching style. In a face-to-face environment, your teaching style and expectations would be emphasized by your actions and subtle indicators. For example, you may value and prefer student collaboration and place desks and chairs in groups for students to work together. In an online class, images can say a lot. You can create a collaborative space for students to work on projects or offer peer supports and link a specific image to that space so students know where to go. You might create a word cloud of words or phrases you typically use when communicating with students and place that in a visible place in the course.

- Use questions as a chance for connection. It's common to see questions or students' moments of confusion as barriers rather than opportunities. Instead of shooting off a quick email to answer a student's question, consider if it may be an opportunity for 
connection. If you are available, give the student a quick call and talk through their question. Or make a quick screencast to send to them. If you use specific tools in your course, consider holding live sessions where you show students how to use the tools and answer questions. Each of these moments provides another connection and an opportunity for students to engage with you.

These strategies may sound familiar and be tactics you implement in your face-to-face classroom. The difference in online teaching is that you must be intentional about sharing your style, expectations, and personality with students. View the online environment as a place to be creative in how you share your passions, perspective, and teaching style. Students are ready and eager to get to know you and feel connected!

\section{Author Bio}

Dr. Tammy Marino has been in the Learning and Development field and Higher Education for over 20 years. She has been a coach, trainer and consultant on topics spanning the Human Capital Management cycle. She has provided instructional design and learning leadership for Higher Education and is an adjunct faculty member at two Community Colleges. She loves designing and delivering dynamic learning experiences both in person and online and is Quality Matters certified for online teaching. 